Intracranial section of the glossopharyngeal and upper roots of the vagus nerves has been recommended, the cardiac dysrhythmia being controlled with atropine, isoprenaline, or transvenous pacemaker. Carbamazepine is known to relieve the pain of uncomplicated glossopharyngeal neuralgia. ${ }^{2}{ }^{3}$ In our first patient the combination of carbamazepine and demand pacemaker abolished both pain and syncope within hours. The pacemaker was later withdrawn. In the second patient both neuralgia and syncope were suppressed by carbamazepine for one year.

By its inhibitory effect on brain stem reflex activity carbamazepine appears not only to be an effective treatment for the pain of glossopharyngeal neuralgia but also to control the more dangerous bradycardia and asystole.

We thank Dr R Bradley for permission to report case 1.

1 Jones, R K, Pennsylvania Medical fournal, 1960, 63, 1113.

${ }^{2}$ Kjellin, K, Muller, R, and Wiken, L, Neurology, 1959, 9, 527.

${ }^{3}$ Crill, W E, Annals of Internal Medicine, 1973, 79, 844.

(Accepted 20 December 1978)

Department of Medical Ophthalmology, St Thomas's Hospital, London SE1

R R JACOBSON, MB, MRCP, medical registrar

$R$ W ROSS RUSSELL, MD, FRCP, physician

\section{Gonoccocal ophthalmia neonatorum caused by beta-lactamase-producing Neisseria gonorrhoeae}

Certain strains of Neisseria gonorrhoeae produce the enzyme betalactamase that destroys the penicillin nucleus, rendering the drug ineffective. In the West these mutant strains probably originated from conjugation between $N$ gonorrhoeae and strains of Escherichia coli which produce beta-lactamase. There is some evidence that resistant strains in the Far East arose from conjugation between the gonococci and Haemophilus influenzae. ${ }^{1}$ Genital gonococcal infection by these penicillin resistant strains were first reported in England and the USA ${ }^{2}$ in 1976. Reports followed from Belgium, Sweden, Norway, Ghana, Singapore, Thailand, Philippines, and Korea. ${ }^{3}$ In Singapore in 1977 22 resistant strains were reported out of a total of 7668 infections $(0 \cdot 29 \%)$. In the first six months of 1978188 were reported out of 4195 infections $(4 \cdot 48 \%)$. The number of gonococcal ophthalmia neonatorum cases reported in 1977 and the first six months of 1978 was 20 and 15 respectively. We report a case caused by a beta-lactamase-producing strain of gonococci. It is the first reported in Singapore and, we think, in the world.

\section{Case report}

An 8-day-old boy attended outpatients for a bilateral purulent eye discharge for five days. Three days before he had been treated by a general practitioner with parenteral and oral penicillin and sulphacetamide eye drops with no apparent improvement. The infant's mother had had a yellowish vaginal discharge for one week before parturition, otherwise she was asymptomatic. Her last sexual intercourse with her husband had been about one month before delivery. She denied other sexual contacts. Her husband admitted having a urethral discharge at about the same time but he had been treated by a general practitioner with full recovery. The patient was unaware of this and thus remained untreated.

Smears from the infant's eyes and the mother's endocervix and urethra showed Gram-negative intracellular diplococci. Specimens were sent to the laboratory for culture for $N$ gonorrhoeae. Gonorrhoea was provisionally diagnosed and both mother and child were admitted. The mother was treated with intramuscular procaine penicillin $4.5 \mathrm{mega}$ units and probenecid $1 \mathrm{~g}$ by mouth. The child was given intramuscular crystalline penicillin 100000 units six-hourly for four doses and crystalline penicillin drops $(10000$ units $/ \mathrm{ml}$ ) were instilled into both eyes, after swabbing with normal saline, every 10 minutes in the first hour, every 30 minutes in the second, third, and fourth hours, and thereafter hourly for 60 hours. Despite this, smears from the child's eyes and mother's endocervix still showed Gramnegative intracellular diplococci after three days' treatment. By then the results of culture of the initial specimens had confirmed the presence of penicillin-resistant strains of gonococci. The mother was then treated with intramuscular kanamycin $2 \mathrm{~g}$ and the child intramuscular kanamycin $1 \mathrm{~g}$ with intensive eye toilet, as described above, using $1 \%$ kanamycin eye drops. Follow-up smear cultures on days 3, 7, and 14 of kanamycin treatment were negative for $N$ gonorrhoeae. Both mother and child have since been well.

\section{Comment}

Crede's method of instilling silver nitrate eye drops to newborns has not been practised in Singapore for many years. The low incidence of gonococcal ophthalmia neonatorum, about $0.07^{\circ}{ }^{\circ}$ of total live births a year, reflects satisfactory control and antenatal screening. But with the increase in cases of genital infections caused by penicillin-resistant gonococci in the East we expect this incidence to rise. We have treated 356 cases of beta-lactamase-producing gonorrhoea with single intramuscular doses of $2 \mathrm{~g}$ kanamycin, with an overall cure rate of $98 \cdot 2^{\circ}{ }_{0}$. We therefore think that kanamycin is very effective.

In a recent study we found that treatment of gonococcal ophthalmia neonatorum with intensive eye toilet alone is unsatisfactory. The failure rate was $18.75^{\circ}{ }^{\circ}$. But combined local and parenteral therapy with penicillin cleared infections in $100^{\circ}{ }^{\circ}$ of cases. ${ }^{\circ}$ We therefore emphasise the importance of combined treatment.

${ }^{1}$ Percival, A, et al, Lancet, 1976, 2, 1379.

${ }^{2}$ British Medical fournal, 1976, 2, 963.

${ }^{3}$ WHO Scientific Group, Neisseria Gonorrhoeae and Gonococcal Infections, WHO Technical Report Series 616, p 124. WHO, Geneva, 1978.

${ }^{4}$ Rajan, V S, Pang, R, and Sng, E H, Singapore Medical fournal, 1978, $19,86$.

(Accepted 5 December 1978)

Middle Road Hospital, Singapore 7

R PANG, MB, DIPVEN, medical officer

L B TEH, MB, MMED, registrar

V S RAJAN, FRCPED, FRCPGLAS, medical superintendent and senior dermatologist

Department of Pathology, Singapore General Hospital, Singapore 3 E H SNG, MB, DIPBACT, senior immunologist

\section{Reactive arthritis associated with Campylobacter jejuni enteritis}

Reactive arthritis, defined as an acute arthritis associated with an infection elsewhere in the body and without the infecting microorganism being present in the joints, may follow infections of the intestinal and urinary tract. The intestinal pathogens Shigella, Salmonella, and Yersinia enterocolitica have been associated with reactive arthritis. We describe a patient who developed an arthritis after enteritis caused by Campylobacter jejuni, a bacterium which has not been described as an aetiological agent in reactive arthritis.

\section{Case report}

A 20-year-old man was seen with arthritis of both ankle joints. Five weeks before he had become suddenly ill with fever $\left(39.5^{\circ} \mathrm{C}\right)$, watery diarrhoea contaminated with blood, anorexia, and weight loss of $6 \mathrm{~kg}$. These symptoms lasted for five days. $C$ jejuni was isolated from the faeces. Two weeks after the onset of the enteritis an acute arthritis of both ankle joints developed. $\mathrm{He}$ had no dysuria, conjunctivitis, skin abnormalities, or lesions of the mucous membranes and no history of bowel or joint complaints. When seen three weeks after the onset of the arthritis the ankle joints were warm, tender, red, and swollen. The other peripheral joints and the spine, skin, nails, mucous membranes, penis, and eyes were normal. Laboratory examination initially showed an erythrocyte sedimentation rate of $40 \mathrm{~mm}$ in 1 hour, which later became normal. Haemoglobin, leucocyte and platelet counts, serum creatinine, urate, cholesterol, liver function tests, and complement factors C3, factor B, and C4 were within normal limits. A PPD skin test was negative. Aspiration of the right ankle joint produced clear yellow synovial fluid. No micro-organisms or polymorphonuclear leucocytes were seen in the Gram smear. Culture of the aspirate failed to grow $C$ jejuni. Bacteriological examination of the stool at this time was also negative for $C$ jejuni as well as for salmonella, Yersinia enterocolitica, and shigella. Serological tests were negative for rheumatoid factors, antinuclear and antiperinuclear antibodies, complement fixing antibodies against Neisseria gonorrhoeae, and agglutinating antibodies against $Y$ enterocolitica types 3 and 9 and $Y$ pseudotuberculosis. When $C$ jejuni were isolated from the stools no 
agglutinating antibodies could be detected against the isolated strain, but by the time the enteritis was over the titre had risen to $1 / 1280$. When we saw the patient in our outpatient clinic the titre had declined to 1/160. After the arthritis had disappeared no antibodies could be detected. Radiological examination of the sacroiliac and ankle joints showed no abnormalities. Tissue typing showed HLA-A 2,28; B 12,27. Eight weeks after the onset of the arthritis all signs and symptoms had disappeared.

\section{Comment}

The findings in this case suggest that the oligoarthritis was reactive to the $C$ jejuni enteritis. The arthritis started two weeks after the onset of the enteritis, and the antibody titre against the isolated campylobacter significantly increased. Other known causes for acute arthritis could be excluded. Moreover, reactive arthritis after certain infections occurs especially in HLA-B 27-positive patients. ${ }^{1}$ This antigen was present in our patient. We do not know of other reports of reactive arthritis associated with $C$ jejuni infections. One report ${ }^{2}$ attributes exacerbations of a Reiter syndrome to Campylobacter fetus infections. This species, however, is distinct from $C$ jejuni. $C$ jejuni is now identified more often as a cause of enteritis. ${ }^{3}$ Possibly, therefore, reactive arthritis after $C$ jejuni infection is not rare and will be diagnosed more often in the future.

1 Aho, K, et al, Arthritis and Rheumatism, 1974, 17, 521.

- Urman, J D, Zurier, R B, and Rothfield, N F, Annals of Internal Medicine, $1977,86,444$.

'Skirrow, M B, British Medical fournal, 1977, 2, 9.

(Accepted 19 December 1978)

Departments of Medicine and Medical Microbiology, Radboud Ziekenhuis, University of Nijmegen, Nijmegen, The Netherlands J H M BERDEN, MD, internist

H L MUYTJENS, MD, microbiologist

L B A VAN DE PUTTE, MD, rheumatologist

\section{Renal carcinoma with thrombocytopenia, clubbing, and hypertrophic osteoarthropathy}

Renal carcinoma has not been reported in association with thrombocytopenia, while clubbing and hypertrophic osteoarthropathy in the absence of pulmonary metastases has also not been described.

\section{Case report}

A 71-year-old man was admitted in December 1974 with aching in his left loin, weight loss of $18 \mathrm{~kg}$ in two months, and clubbing of fingers and toes. His erythrocyte sedimentation rate (ESR) was $120 \mathrm{~mm}$ in the first hour (Westergren). Skeletal $x$-ray survey and bone scan showed hypertrophic osteoarthropathy of the tibiae, fibulae, and femora. Investigations with normal results included the following: urine microscopy, intravenous urography, blood and platelet counts, chest radiograph, sputum cytology, bronchoscopy with washings for cytology, barium enema, barium meal, liver biopsy, faccal fat excretion, urinary and serum protein electrophoresis, and bone marrow aspiration. His left loin pain and his raised ESR persisted until his death.

In April 1976 a radiograph of the renal areas was normal, as was his platelet count and findings on urine microscopy. In July 1977 he was found to have developed asvmptomatic thrombocytopenia (platelet count below $40-10^{9} / 1$. At that time he was receiving regular paracetamol and dextropropoxyphene (Distalgesic) tablets for his loin pain, but the thrombocytopenia was unaffected by the withdrawal of the drug.

He received no other medication during the illness. The cause of the thrombocytopenia was not identified, the results of the following being normal: bone marrow aspiration and trephine, diffuse intravascular coagulation screen, serum and urinary protein electrophoresis, estimation of immunoglobulins and antinuclear factor, liver function tests, urine microscopv, platelet surface IgG estimation, and tests for platelet antibodies with and without paracetamol and dextropropoxyphene. In December 1977 the spleen was just palpable. In February 1978 the patient was found to have haematuria. Urine microscopy had been normal on six previous occasions. An abdominal radiograph showed calcification within the upper pole of the left kidney; intravenous urography and renal arteriography showed that the calcification was within a renal carcinoma. The previous $x$-ray films were reviewed and again passed as normal. An inoperable locally invasive renal carcinoma was found at laparotomy. The patient recovered sufficiently to go home for a month, but was subsequently readmitted with a terminal bilateral bronchopneumonia. He had never had macroscopic haematuria.

Necropsy-A large, poorly differentiated renal cell carcinoma with pseudosarcomatous change in some areas was found. Tiny foci with the more typical pattern of renal papillary carcinoma still remained and a thin rim of normal kidney surrounded parts of the tumour. The tail of the pancreas, the left adrenal, and the spleen were affected by a mass of necrotic tissue, and multiple, small, wedge-shaped infarcts with associated thrombosed vessels were seen in the spleen. No definite invasion of the spleen by malignant cells was seen, and no viable tumour was identified in the necrotic material. There were no secondary deposits in any other organ and the left renal vein was not invaded. His terminal bronchopneumonia was confirmed.

\section{Comment}

The variable clinical presentation and course of renal carcinomas are well known. ${ }^{2}$ This patient presented with loin pain three years before he had other symptoms or radiological evidence of renal carcinoma. Hypertrophic osteoarthropathy and clubbing have been described only in association with pulmonary metastases and have disappeared after resection of the metastases. ${ }^{3}$ In this case only the legs were affected by the hypertrophic osteoarthropathy, although the fingers were clubbed, and no metastases were seen. Haematuria occurred only when the thrombocytopenia was well established. The thrombocytopenia had no clear cause and contrasts with the more usual thrombocythaemia seen with carcinomas. The thrombocytopenia may be related to splenic infarction.

We thank Dr R W E Watts for permission to report this case.

${ }^{1}$ Salm, R, and Pollok, R, British Medical fournal, 1952, 2, 266.

2 Bruce, J, and Macleod, J G, British Medical fournal, 1955, 1, 1323.

${ }^{3}$ Goldstraw, P, and Walbaum, P R, Thorax, 1976, 31, 205.

(Accepted 20 December 1978)

Northwick Park Hospital, Harrow, Middlesex

P T WILMSHURST, BSC, MRCP, medical registrar (now cardiology registrar, St Thomas's Hospital, London)

K R MILLS, PHD, MRCP, senior house officer (now senior house officer in neurology, National Hospital, Queen Square, London)

Y J DRABU, MB, CHB, senior house officer in pathology

\section{Acute renal failure after TAB and cholera vaccination}

Reactions to TAB and cholera vaccination ranging from local erythema to constitutional disturbance are commonplace. ${ }^{1}$ We record here an episode of acute renal failure and hepatitis after vaccination, which apparently has never been reported.

\section{Case report}

A fit 21-year-old man who several years earlier had undergone vaccination with $T A B$ and cholera was revaccinated with typhoid A and B and cholera $0.5 \mathrm{ml}$ subcutaneously. Within one hour he vomited and complained of headache and abdominal pain. He vomited several times during the following night and one episode of diarrhoea occurred; fluids were encouraged throughout this period. He developed myalgia. The next day he had neck stiffness and his temperature rose to $37.4^{\circ} \mathrm{C}$. On the third day of the illness he was admitted to hospital because he had been anuric since the injection.

Examination showed jaundice, but he was not clinically dehydrated. There was obvious tenderness of the neck, limb, and abdominal wall muscles. The blood pressure was $90 / 70 \mathrm{~mm} \mathrm{Hg}$ and the pulse rate was 80 beats $/ \mathrm{min}$, regular and of good volume. The heart sounds were normal and the chest clear. The results of examination was otherwise normal.

Investigations showed : haemoglobin $15 \cdot 2 \mathrm{~g} / \mathrm{dl}$, white cell count $23.6 \times 10^{9} / 1$; blood concentrations of urea $23.0 \mathrm{mmol} / 1(138 \mathrm{mg} / 100 \mathrm{ml})$, potassium $3 \cdot 8$ $\mathrm{mmol}(\mathrm{mEq}) / 1$, sodium $129 \mathrm{mmol}(\mathrm{mEq}) / 1$, total $\mathrm{CO}_{2} 20 \mathrm{mmol}(\mathrm{mEq}) / \mathrm{l}$, and creatinine $0.38 \mathrm{mmol} / 1(4.4 \mathrm{mg} / 100 \mathrm{ml})$. Bilirubin concentration was raised at $75 \mu \mathrm{mol} / 1(4.5 \mathrm{mg} / 100 \mathrm{ml})$, alanine transaminase at $160 \mathrm{IU} / 1$, and aspartate transaminase at $85 \mathrm{IU} / 1$; alkaline phosphatase concentration was normal.

There was no history of exposure to nephrotoxins, contact with infectious disease, or excessive exercise. The following blood tests all gave normal or negative results: blood culture, viral studies, Paul-Bunnell test, Leptospira complement fixation test, immunoglobulin and complement estimations, 